\title{
Comunicação: condição ou impossibilidade humana?
}

\author{
Gabriel Sausen Feil
}

Resumo: Nietzsche traz a comunicação como condição humana; por outro lado, Deleuze e Guattari afirmam que a comunicação não é possível aos humanos. Este artigo se apropria desse impasse, buscando mostrar que as duas possibilidades têm sentido, sem que isso implique um contrassenso. Para tanto, realiza uma discussão conceitual envolvendo o pensamento dos mencionados autores e ainda o modo como um texto brasileiro de teorias da comunicação lida com essa problemática. Por fim, mostra que a argumentação nietzschiana acerca da natureza comunicativa dos humanos é complementar àquela que Deleuze e Guattari usam para mostrar a impossibilidade de humanos comunicarem-se e que, se as argumentações parecem ser contraditórias, é apenas em função de distintas construções conceituais para o termo "comunicação".

Palavras-chave: comunicação humana; comunicação animal; teorias da comunicação; Nietzsche; Deleuze; Guattari

Abstract: Communication: a human condition or impossibility? - Nietzsche considers communication a human condition; Deleuze and Guattari, on the other hand, argue that communication among humans is not possible. This article examines this impasse, seeking to demonstrate that the two possibilities make sense, without implying any contradiction. To this end, a conceptual discussion is made of the rationale of the aforementioned authors, and of how a Brazilian text on communication theories deals with this problem. Lastly, the paper shows that Nietzsche's argument about the nature of human communication complements the one Deleuze and Guattari propose to demonstrate the inability of humans to communicate, and that although these arguments appear to be contradictory, it is only due to different conceptual constructions of the term "communication."

Keywords: human communication; animal communication; communication theories; Nietzsche; Deleuze; Guattari

No aforismo 354 de A gaia ciência, Friedrich Nietzsche (2012) traz a comunicação como uma condição humana (apesar de não usar, literalmente, essa última expressão). Por outro lado, os pensadores franceses Gilles Deleuze e Félix Guattari (1995a), ainda que 
profundamente devedores do pensamento nietzschiano, afirmam, no platô "Postulados da linguística", que a comunicação não é possível para os humanos. O presente artigo se apropria desse dilema; não para solucioná-lo e para indicar qual é a alternativa correta, mas para, ao contrário, mostrar que as duas possibilidades têm sentido, sem que isso implique qualquer contradição. Para tanto, realiza uma discussão conceitual envolvendo não apenas o mencionado aforismo e o mencionado platô, mas também o modo como um texto brasileiro de teorias da comunicação lida com essa problemática.

\section{A comunicação como condição humana}

Na perspectiva nietzschiana, a consciência é supérflua e desnecessária para o mundo. É isso que justifica a pergunta: "para que então consciência, quando no essencial é supérflua?" (NIETZSCHE, 2012, p. 221, grifo do autor). Se não tem a menor importância para o mundo - o mundo existe independentemente dela - por que a consciência? É na resposta do autor que se encontra a tese que dá consistência a esta primeira seção: "bem [...], parece-me que a sutileza e a força da consciência estão sempre relacionadas à capacidade de comunicação de uma pessoa [...], e a capacidade de comunicação, por sua vez, à necessidade de comunicação" (2012, p. 221, grifo do autor). Ou seja, apesar de ser supérflua para o mundo, é condicional e constitutiva para a sobrevivência da humanidade.

$\mathrm{Na}$ afirmação do autor, ainda fica subentendido que a consciência, ao contrário do que se propaga, sobretudo, no senso comum, não tem nada de especial e/ou superior: assim como o porco-espinho não sobreviveria sem o espinho, uma vez que este lhe garante proteção, o humano não sobreviveria sem a consciência, uma vez que esta lhe permite se comunicar, tendo garantido, a exemplo do mencionado animal, a possibilidade de defender-se. É por isso que, considerando o hábito histórico de dar nome às coisas a partir dos seus diferenciais mais salientes (o diferencial saliente do porco-espinho é o espinho), pode-se chamar o humano de "pequena-razão", já que, na perspectiva nietzschiana, todos os corpos têm a grande razão, porém, somente o humano tem a pequena, que é, justamente, a consciência. Está-se, nesse sentido, chamando-o pela sua peculiaridade mais saliente, assim como procedemos com o porco-espinho, o tubarão-martelo, o peixe-espada etc.

É importante que aqui se perceba o destaque que esse argumento de Nietzsche dá ao tema da comunicação; afinal, está afirmando que se o animal homem (tornando-se humano ou, nos termos recém-apresentados, pequena-razão) desenvolveu consciência, não foi devido a uma luz celestial ou a uma graça divina, mas devido à sua necessidade de comunicar-se.

Não apenas a vida, em geral, não necessita da consciência, como a vida dos próprios homens, em princípio, também não necessitava. Podiam "pensar, sentir, querer, recordar [...]: e, não obstante, nada disso precisaria 'entrar na consciência'" (NIETZSCHE, 2012, p. 221). Porém, passaram a precisar se comunicar entre si, no sentido de que, se tal habilidade não tivesse sido desenvolvida, a espécie não teria sobrevivido. Ao contrário, portanto, 
de se tratar de um atributo especial que coloca o seu detentor no topo da hierarquia existencial, a consciência foi desenvolvida apenas porque o homem careceu que as suas necessidades fossem recorridas aos outros, e não somente a si mesmo, como no caso de tantos outros animais.

A consciência desenvolveu-se apenas sob a pressão da necessidade de comunicação [...], e também se desenvolveu apenas em proporção ao grau dessa utilidade. Consciência é, na realidade, apenas uma rede de ligação entre as pessoas - apenas como tal ela teve que se desenvolver: um ser solitário e predatório não necessitaria dela [...]: ele precisava, sendo o animal mais ameaçado, de ajuda, proteção, precisava de seus iguais, tinha de saber exprimir seu apuro e fazer-se compreensível - e para isso tudo ele necessitava antes de 'consciência', isto é, 'saber' o que lhe faltava, 'saber' como se sentia, 'saber' o que pensava (NIETZSCHE, 2012, p. 222, grifo do autor).

Nietzsche retira a humanidade de seu pedestal, construído com base no pressuposto de que a consciência e a razão são dotadas de um valor especial e superior. Em Sobre verdade e mentira no sentido extramoral, afirma: "somente seu possuidor e genitor [do intelecto] o toma tão pateticamente, como se os gonzos do mundo girassem nele" (1978b, p. 45).

Ao contrário de uma visão que eleva o ser humano ao transcendente, a visão nietzschiana enxerga o mundo não a partir da consciência, mas a partir dos impulsos, sendo alguns deles apreendidos para formá-la. Nesse sentido, o pensamento é muito maior do que a consciência, de maneira que a comunicação diz respeito somente a ele, e o pensamento mesmo jamais se limita a ela. Encontramos na comunicação não o pensamento que é de fluxo contínuo e incontrolável, mas o pensamento tornado comum, tornado rebanho.

O ser humano, como toda criatura viva, pensa continuamente, mas não o sabe; o pensar que se torna consciente é apenas a parte menor, a mais superficial, a pior, digamos: - pois apenas esse pensar consciente ocorre em palavras, ou seja, em signos de comunicação, com o que se revela a origem da própria consciência. Em suma, o desenvolvimento da linguagem e o desenvolvimento da consciência (não da razão, mas apenas do tomar-consciência-de-si da razão) andam lado a lado (NIETZSCHE, 2012, p. 222, grifo do autor).

Para Nietzsche, a consciência não é uma característica do homem propriamente dito, "mas antes daquilo que nele é natureza comunitária e gregária" (2012, p. 223), de maneira que as ações singulares, diferentes por natureza, parecem não ser mais a partir do momento em que são traduzidas "para a consciência" (p. 223). Ou seja, apesar de as experiências serem absolutamente únicas, incomparáveis, parecem não ser mais quando traduzidas em signos convencionados. É por isso que, numa passagem de $A$ filosofia na época trágica dos gregos, Nietzsche conclui o aforismo 03 da seguinte maneira: "assim 
Tales contemplou a unidade de tudo o que é: e quando quis comunicar-se, falou da água!" (1978a, p. 33).

A natureza da consciência animal ocasiona que o mundo de que podemos nos tornar conscientes seja só um mundo generalizado, vulgarizado - que tudo que se torna consciente por isso mesmo torna-se raso, ralo, relativamente tolo, geral, signo, marca de rebanho, que a todo tornar-se consciente está relacionada uma grande, radical corrupção, falsificação, superficialização e generalização (NIETZSCHE, 2012, p. 223, grifo do autor).

Quando, em Assim falava Zaratustra, Nietzsche, através de seu mais famoso personagem, diz que "o homem é corda estendida entre o animal e o Super-homem" (2010, p. 20), está expressando a ideia de que enquanto o animal está ao bem querer de seus instintos, e que o Super-homem está com os seus instintos livres para fazer deles o que desejar, o homem se encontra como escravo de sua própria consciência, amarrado à sua própria linguagem.

Ora, mas esta seção não vem procurando mostrar que, na visão nietzschiana, a comunicação é necessária aos humanos? Então, por que criticá-la? É que, apesar de mostrar a condicionalidade da comunicação, o autor procura, ao mesmo tempo, mostrar que a capacidade comunicativa, aliada à consciência, não tem nada de especial, a não ser para o seu próprio detentor (assim como o espinho é especial para o porco-espinho, e não para o mundo).

Porém, o fato de a comunicação pressupor a banalização e a vulgarização, não significa que nisso não possa haver criação e singularidade. Diz Nietzsche, em Humano, demasiado humano: "três quartos de Homero são convenção" (1978c, p. 147). Sua intenção é defender que mesmo o artista não é pura criação; pelo contrário, a criação é apenas o que se excede dos aspectos que, apesar de ordinários, são constitutivos das obras artísticas. Nietzsche, então, diz que todo artista se insere numa espécie de convenção artística, entendida como os meios usados por eles para serem ouvidos, principalmente por outros artistas (o interesse principal do autor é pelos poetas e músicos gregos, que queriam vencer seus rivais). Há uma "linguagem comum laboriosamente aprendida com a qual o artista pode efetivamente comunicar-se. [...] A primeira condição é que seja também prontamente entendido: o que, porém, só é possível através da convenção" (p. 147, grifo do autor). Apesar de a singularidade da obra não se dar no âmbito da convenção, é esta que possibilita a transcendência daquela, sendo nesse extrapolar que o artista se arrisca e se permite criar. Aquilo que o artista inventa é sempre além da convenção, porém, precisa dela para ter o que transgredir; para ter do que se diferenciar. Por um lado, portanto, não fugir da convenção é mediocridade (a criação jamais está na convenção); por outro, abdicar da convenção é impossível, dada a condicionalidade da comunicação.

Comunicar, então, implica tornar comum, o que possibilita o relacionar-se na ausência dos objetos referidos. Diz Nietzsche, em Além do bem e do mal: "toda comunidade 
torna, de algum modo, alguma vez, em algum tempo - comum, vulgar" (2005, p. 173). De qualquer maneira, comunicar é preciso porque ao homem se exigiu um novo componente: a fragmentaridade. Apesar de os demais animais, as plantas e as matérias relacionarem-se, não são capazes de unirem (mesmo que tal união seja somente uma ilusão) forças naturalmente diferentes no interior de categorias. E, se assim exigiu-se ao humano, foi pela necessidade de comunicação, sem a qual não sobreviveria, assim como ao jacaré exigiu-se dupla respiração, ao camelo corcovas para armazenar água e ao tamanduá bico fino para sugar formigas. Sem consciência não há fragmentarização, sem fragmentarização não há comunicação e nada além do caos. Comunicar se torna necessário, justamente, para quem não pode viver no caos. "Chega, vamos parar de nos comunicar!": o pequena-razão não tem essa opção, assim como não pode arrancar a cabeça quando estiver com dor (pressuposto que queira permanecer vivo).

Se se pudesse imaginar, hipoteticamente, o homem vivendo sozinho, chegar-se-ia à conclusão de que já estaria extinto, ou não seria do jeito que se conhece: esse jeito é social, de modo que imaginar o homem numa situação assim é como imaginar um leão falante. O recém-nascido precisa do outro não somente para cuidados fisiológicos, como também para o seu desenvolvimento mental, o qual diz respeito, antes de tudo, ao desenvolvimento filogenético que potencializa esse organismo a se comunicar com o outro e, através dessa relação, produzir sentido. Em suma, tratando-se do pequena-razão, está-se falando de um ser que se comunica; aliás, na perspectiva desta seção, somente ele, dentre todos os seres, comunica-se.

\section{A comunicação como impossibilidade humana}

Pensamento contrário do enunciado que finaliza a seção anterior é o de Deleuze e Guattari: para eles, a comunicação é impossível para o humano e possível somente para alguns animais, como a abelha (1995a, p. 13-14). Uma abelha se comunica porque transmite uma informação exata a outras abelhas, diferentemente do humano que se relaciona por sobrecodificações, por traduções de códigos. Nesse sentido, a linguagem é feita "para a tradução, não para a comunicação" (1995c, p. 119).

Segundo esse raciocínio, portanto, os humanos não comunicam, mas fazem traduções. Se há uma possibilidade de haver comunicação, essa somente é viável para códigos genéticos ou para alguns animais, os quais são capazes de transmitirem a mesma informação que recebem. Aos humanos é possível somente traduzir porque a eles a mesma informação não existe e não há como existir, não se tratando, portanto, de uma questão de aperfeiçoamento do ato comunicativo (não é uma questão de diminuir os ruídos, tal como queria a teoria matemática da comunicação). É nesse sentido que, para Deleuze e Guattari, a linguagem não comunica signos, e sim traduz singularidades; eles não acreditam "que a narrativa consista em comunicar o que se viu, mas em transmitir o que se ouviu, 
o que um outro disse" (1995a, p. 13). Aquilo que alguém ouviu não é mais aquilo que o interlocutor desse alguém falou.

Se os humanos são constituídos pela linguagem, é porque cada um deles fala uma língua diferente (DELEUZE e GUATTARI, 1995c, p. 119), sendo necessárias formas de expressão capazes de traduzir as diferenças, o que é desnecessário para as abelhas, as quais falam - todas elas - a mesma língua (mesmo código). Diz-se que o português fala uma língua e o espanhol outra, o que é verdade; porém, não é preciso ter dois idiomas para ter duas línguas em questão: um português não fala a mesma língua do que o outro português ao seu lado. Em outras palavras, o humano lida com a linguagem justamente porque não pode comunicar efetivamente, ao contrário da abelha, que "é capaz de comunicar o que viu, mas não de transmitir o que lhe foi comunicado" (1995a, p. 13). Ou seja, se por um lado a abelha pode comunicar, por outro não pode traduzir: a abelha que percebe um alimento pode passar a informação para aquelas que não o perceberam; porém, as abelhas que não perceberam o alimento não são capazes de transmitir nenhuma informação. É preciso, a elas, que haja o primeiro objeto, e que ele efetivamente exista, não sendo o caso da linguagem, a qual "não se contenta em ir de um primeiro a um segundo, de alguém que viu a alguém que não viu, mas vai necessariamente de um segundo a um terceiro, não tendo, nenhum deles, visto" (p. 14).

Quando se diz uma palavra qualquer: "Platão", por exemplo, tal palavra não é um objeto original, mas um conjunto de virtuais que não deixam de vibrar ao serem ouvidos. Ao humano, cabe traduzir os efeitos que essas vibrações lhe provocam, e não repassar a informação "Platão" que havia recebido. Existem muitos platões na palavra "Platão", "e todos os tipos de voz em uma voz" (DELEUZE e GUATTARI, 1995a, p. 13).

É por isso que a tradução é sempre uma mentira (produtiva)! Trata-se de uma nova composição e, nesse sentido, de uma nova criação. Diante disso, quando se diz algo como "ao citar tal escritor, pretende-se somente fazer uso de algumas de suas inúmeras contribuições para construir ideias novas...", não é necessário dizer, porque isso vai acontecer, deve acontecer. É redundante falar em pensamentos incompatíveis, já que todo pensamento é incompatível, a compatibilidade não passando de uma tentativa de se afunilar o pensamento. O pensamento não é comunicativo; é contraditório e incoerente por natureza.

Não há tradução que não deixe escapar fluxos de elementos indiscerníveis, e é justamente por isso que se trata de tradução e não de comunicação. Tratando-se de mundo, na perspectiva deleuzoguattariana, a diferença é ontológica, de modo que o "mesmo" não passa de uma ilusão. É por isso que o problema de Deleuze e Guattari é, sobretudo, com os atos submetidos à doxa, os quais se iludem com a possibilidade de exercerem uma comunicação total, de obterem um consenso e de estabelecerem relações verdadeiramente democráticas, como se os fluxos pudessem ser obstruídos definitivamente. Para que o ato comunicativo fosse revisto por esses autores, seria necessário que pressupusesse a sua não 
realização completa, ao modo de uma tradução. Talvez um ato que buscasse ser potente em vez de claro, interessante em vez de entendido. Seria necessário pressupor que o caos existe desde sempre, mas que a comunicação não, que esta é recente, uma novidade para o mundo, e que, por isso, não poderia reduzir a vida ao seu sistema de sentidos e de entendimentos. Para um anarqueonte ${ }^{1}$ como Deleuze, o primado é dos fluxos: não há banalização que não seja atravessada por fluxos que a impelem a fugir, e, nesse sentido, em vez de perguntar "onde está a diferença?", pergunta: "ora, onde ela não estaria?".

Assim, considerando o pensamento de Deleuze e Guattari, somente é possível falar em comunicação humana se esta for entendida como uma atividade ilusória.

\section{A problemática num texto de teorias da comunicação}

A intenção desta seção é mostrar como o conceito de comunicação aparece na teoria comunicacional e analisar as implicações que tal conceito traz para a problemática "comunicação: condição ou impossibilidade humana?". Para isso, trabalha-se com dois textos de Luiz C. Martino, ambos constitutivos do livro Teorias da comunicação: conceitos, escolas e tendências. Escolho esses textos por se deterem especificamente e intencionalmente na problemática em questão.

Em "De qual comunicação estamos falando?", Martino argumenta que o senso comum admite, "sem maiores problemas", "que os animais se comunicam", bem como os aparelhos técnicos "(dois computadores ligados por modem, por exemplo)" (2001a, p. 12), mas acaba por afirmar que, "em sua acepção mais fundamental, o termo 'comunicação' refere-se ao processo de compartilhar um mesmo objeto de consciência, ele exprime a relação entre consciências" (p. 14-15). Com isso, aproxima-se da versão nietzschiana vista na primeira seção deste artigo, em que a atividade comunicativa se liga ao desenvolvimento da consciência e, portanto, diz respeito somente aos seres humanos: "o ser humano é um ser da comunicação: [...] as coisas não se apresentam ao ser humano de forma direta, mas são construídas graças à mediação [...], conhecimento e reconhecimento de outrem" (MARTINO, 2001a, p. 23).

O ser humano é um ser da comunicação já por conta da própria criação das noções, das ideias e dos conceitos envolver a atividade comunicativa. Em outras palavras, não há a possibilidade de ele se desfazer da comunicação: "no caso humano, nós não temos senão relações" (MARTINO, 2001a, p. 23). Não há atividades humanas que não sejam constituídas por e nas relações. O que está em questão num choque entre dois corpos, por exemplo, já não é apenas o choque em si, mas o sentido que o humano dá a esse fenômeno. E ainda que tal humano desejasse que isso fosse diferente, nada poderia fazer,

1 Anarqueonte (a invenção é de Jean-Claude Dumoncel): em vez de se admirar com as formas, Deleuze se admira com os fluxos, com as matérias sem formas. Os fluxos existem sempre, de modo que são as formas que lutam por um minuto de existência (TADEU; CORAZZA; ZORDAN, 2004, p. 193-197). 
já que jamais se apropria do objeto em si, mas apenas da leitura que ele mesmo faz desse objeto. O suposto original sempre se perde! É isso, aliás, que diferencia as relações humanas das dos demais seres orgânicos e das dos seres brutos, os quais experimentam os efeitos em si, sem com que esses "passem" pelas redes da consciência.

É por isso que aqui se prefere deixar o termo "comunicação" apenas para o caso dos humanos $^{2}$ (o próprio Martino também acaba por fazer essa sugestão). Assim, defende-se que o ser humano interage e comunica, mas que os demais seres, incluindo os outros animais ${ }^{3}$, somente interagem. Comunica-se quando há o entendimento (ou, mais propriamente, a ilusão de entendimento) a partir do reconhecimento de signos ou quando há a consciência do não reconhecimento (trata-se de uma relação feita de símbolos que foram tornados reconhecíveis). E interage quando há o contato com qualquer estranho, vivo ou não, independentemente de haver entendimento. Duas substâncias químicas jamais vão se comunicar, mas podem interagir, pois, mesmo desprovidas de consciência, agem, produzem efeitos e se deslocam no espaço, modificando a realidade. E não agem sozinhas, elas "inter-agem". Esse mesmo sistema pode ser adaptado à interação de dois objetos, os quais corroem, amassam, dilatam, à interação entre substâncias químicas e objetos ou ainda à interação dos demais animais. Por mais que provoquem efeitos, por mais que eles possam ser mais potentes que os efeitos provocados pelo ser humano, não há comunicação nessas relações porque não há a possibilidade de simbolização, sendo o símbolo entendido como a abstração da realidade, como a possibilidade de se referir a um objeto mesmo que ele esteja ausente. É precisamente a simbolização que diferencia a comunicação da "simples" interação.

Na perspectiva deste artigo, a simbolização é nada mais do que o agrupamento de singularidades, proporcionando que o naturalmente diferente seja comunicado. Do "ponto de vista do caos", somente o que há é a diferença; são singularidades absolutas. Uma simbolização, por sua vez, é a fragmentação do caos, a qual visa colocar dentro de um mesmo símbolo elementos que são, em verdade, diferentes. Sem esse processo, não há diálogo. Isso significa que a comunicação lança mão da banalização em prol de se tornar possível.

Martino mostra que concorda com isso quando afirma que "comunicar é simular a consciência de outrem, tornar comum [...] um mesmo objeto mental (sensação, pensamento, desejo, afeto)" (2001a, p. 23). E ainda que Nietzsche não use a ideia de "mesmo objeto mental" (prefere as ideias de generalização, fragmentação e banalização - visto que não acredita na possibilidade de o "mesmo" existir), pode-se notar que Martino faz uma apropriação do já mencionado aforismo nietzschiano, sobretudo, no que

2 Sugere-se aqui uma distinção de termos a ser usada em teorias da comunicação: a) o termo "Comunicação" (com " c" maiúsculo) deve ser reservado à área do saber e à pesquisa comunicacional; b) "Comunicação Social" ao curso de nível superior; c) "comunicação" (com "c" minúsculo) à característica constitutiva do ser humano; d) "meios de comunicação" aos dispositivos criados com o intuito de fazer comunicação estratégica. A fim de articular os quatro termos, pode-se dizer que o primeiro é estudado pelo segundo, que envolve o estudo do terceiro e, finalmente, particulariza-se (diferenciando-se das demais áreas) por ver a sociedade e o conhecimento pela ótica do quarto.

3 Vigotski sugere que a interação dos animais seja uma interação por "contágio". Seus movimentos e seus gritos não comunicam, mas contagiam (2001, p. 11). 
tange a relação entre a consciência e a comunicação. Não diz que apenas humanos se comunicam (tanto é que usa exemplos de comunicação entre seres brutos e entre outros seres orgânicos), mas diz que a comunicação que interessa à Comunicação (entendida como uma área do saber) é a caracterizada (e nisso se diferencia da possibilitada pelos demais seres) pela relação entre consciências, promovida por códigos que se colocam no lugar dos objetos referenciados. E isso acontecendo não em função de uma escolha pessoal, mas de uma necessidade: o humano não tem a opção de se relacionar diretamente com a coisa; pode apenas interpretá-la. Considerando que é a partir dessa relação que o homem se torna humano, pode-se dizer que a comunicação, em Martino, é uma condição humana, tal como Nietzsche expressa na passagem de A gaia ciência (2012).

No modo de lidar do autor, a ideia de que a comunicação é humana passará a funcionar, em "Interdisciplinaridade e objeto de estudo da comunicação", como um dos pressupostos da construção do objeto próprio à Comunicação. Mas, ao mesmo tempo, como um pressuposto insuficiente:

Mesmo tendo restringido o sentido de 'comunicação' às relações entre os seres humanos, isto não é suficiente para demarcar um domínio específico de estudo, o qual corresponderia a uma disciplina particular denominada 'Comunicação'. Isto somente será possível levando-se em conta as diferenças de abordagem em relação ao fenômeno humano da comunicação (MARTINO, 2001b, p. 25).

É nesse sentido que Martino acrescenta um segundo pressuposto: o objeto da Comunicação se constitui não apenas de fenômenos comunicativos "restritos à dimensão humana" (primeiro pressuposto), como também de fenômenos "mediatizados por dispositivos técnicos" (segundo pressuposto) (2001b, p. 31). O primeiro, sozinho, torna-se insuficiente a partir do momento em que, do século XVIII em diante (isso Martino já havia colocado no primeiro dos dois textos aqui referenciados), a comunicação "deixa de ser [apenas] uma prática social imediata e constitutiva da consciência humana ou das relações interpessoais, para se tornar um exercício coletivo enquanto estratégia de poder" (2001a, p. 19).

Isso significa que Martino se insere no pensamento de Nietzsche que entende a comunicação como uma condição humana, mas acrescenta uma segunda questão, visto que o seu foco é a construção de um problema que seja específico da Comunicação como área do saber.

Distinguimos aí: 1) o problema filosófico da comunicação enquanto fundamento do homem [aqui repete Nietzsche]; 2) o problema histórico da tomada de significação dos processos comunicativos a partir da emergência de um tipo de organização coletiva determinada [aqui acrescenta um segundo pressuposto] (MARTINO, 2001b, p. 31).

Logo após esse fragmento, aliás, Martino cita, buscando exemplificar o ponto " 1 ", o aforismo 354 de A gaia ciência. Já para exemplificar o ponto " 2 ", diz que esse se refere à 
"questão histórica das transformações nas estruturas coletivas" (2001b, p. 32), acontecidas a partir do século XVIII, as quais fizeram com que o tema da comunicação deixasse de ser apenas um fundamento constitutivo, para passar a funcionar como um diferencial estratégico nos planejamentos de corporações, empresas, políticos e/ou estados.

O processo comunicativo deixa de ser analisado em sua generalidade, não sendo mais tratado como o fundamento da consciência humana [...]; ele passa a ser investido como estratégia racional de inserção do indivíduo na coletividade. Não se trata mais de abordar a comunicação como uma instância indissociável da vida em coletividade (MARTINO, 2001b, p. 33).

Na sequência, Martino diz que o ponto "1" representa "a possibilidade de estabelecer um quadro de referências para uma comparação do homem frente aos outros animais, possibilidade então de fundamentar a questão da especificidade (ou essência) humana em uma base não metafísica" (2001b, p. 33). Ou seja, trata-se de uma forma de identificar um diferencial do homem sem precisar lançar mão de uma crença transcendental.

A fim de complementação, torna-se pertinente dizer (sobre a comunicação ser possível somente aos humanos) que Antônio Hohlfeldt, numa nota de rodapé de "As origens antigas: a comunicação e as civilizações", afirma: "alio-me àqueles que entendem ser a comunicação uma capacidade única do ser humano por dar-se em condições de ausência do objeto referido, fenômeno impossível aos demais seres vivos, animais ou vegetais" (2001, p. 61). Nesse sentido, parece, de fato, que se relacionar com as coisas na ausência do objeto referido é o critério usado para restringir a relação comunicativa aos seres humanos.

\section{Conclusão - Condição e impossibilidade a um só tempo}

Até aqui se viu que Nietzsche traz a comunicação como condição humana (seção "1"), Deleuze e Guattari como impossibilidade humana (seção "2") e que Martino, um teórico da comunicação, acompanha o raciocínio nietzschiano e acrescenta o critério do dispositivo técnico, uma vez que o seu foco é apresentar uma comunicação que seja de interesse exclusivo da área comunicacional (seção "3"). Agora, dedica-se a quarta seção ao empreendimento de mostrar que, apesar de parecer que o posicionamento de Nietzsche está em contradição com o de Deleuze e Guattari, estão, em verdade, em sintonia.

É que, quando Nietzsche expressa a comunicação como uma condição humana, está se referindo ao fato de que, quando o intelecto humano desenvolve tal capacidade, a linguagem passa a possibilitar a abstração da realidade, de maneira desvinculada às experiências concretas. Essa abstração somente tem sentido porque é coletiva (de rebanho), permitindo que os humanos compartilhem uma mesma realidade imaginária. Acontece que essa é uma ilusão, uma mentira, mesmo que tal mentira seja essencial para a sobrevivência humana ${ }^{4}$. Eis a grande questão: ainda que o compartilhamento seja essencial, não significa

4 Aqui há uma relação direta com a problemática do niilismo: ainda que o mundo não tenha sentido algum, o ser humano precisa de um sentido para viver. 
que seja, de fato, possível! Não há como partilhar de um mesmo plano, de modo que o compartilhamento não passa de uma simplificação, acima de tudo, funcional. É por isso que Deleuze e Guattari dizem que se trata não de comunicação, mas de tradução dos códigos da natureza.

Em relação à necessidade funcional de abstrair, generalizar e fragmentar, os próprios Deleuze e Guattari afirmam a necessidade de, por exemplo, elaborar-se conceitos: "é apenas sob essa condição que pode sair do caos mental" (1992, p. 27). Ainda que o conceito tenha uma conotação específica na filosofia desses autores, é certo que há uma preocupação em mostrar sua importância como possibilidade de compreensão; afinal, "se este conceito não funcionasse no campo perceptivo, as transições e as inversões se tornariam incompreensíveis, e não cessaríamos de nos chocar contra as coisas, o possível tendo desaparecido" (p. 31). Para que as relações humanas se tornassem possíveis, o homem se tornou "um animal segmentário" (1995b, p. 83).

Todo o esforço da consciência em comunicar não passa, entretanto, de uma ilusão, a qual se dirige, inclusive, contra as forças da natureza. A comunicação, apesar de banalizar, produz, sempre, diferenças. A pura comunicação não é possível, há um fluxo que vaza; um fluxo necessariamente mais forte do que o pensamento fragmentado.

É possível, então, dizer que a comunicação é o que diferencia os humanos dos demais seres e, ao mesmo tempo, dizer que é uma tarefa impossível para eles. E que, por isso, a comunicação é, concomitantemente, condição e impossibilidade humana. Ao afirmar-se aqui ser a comunicação o elemento que diferencia os humanos dos demais seres, está-se considerando a possibilidade de eles se iludirem de que a sua comunicação efetivamente comunica. Nesse caso, essa competência seria possível somente aos humanos, porque apenas eles são capazes de enganar-se, de referir-se a objetos mesmo que estejam ausentes. Mas, para Deleuze e Guattari, essa é justamente a prova do contrário, pois para se referir a um objeto ausente é preciso traduzi-lo, não comunicá-lo, porque o objeto em si não existe, o que está em questão é somente a sua referência.

Acontece que, apesar de impossível aos humanos, a comunicação é ainda assim realizável: banalizar é realizável, mesmo que esse banal não seja jamais efetivamente comum. O problema não está na comunicação, mas, especificamente, naquela que quer comunicar, que quer efetivamente tornar comum; é justamente quando o homem, pretensioso homem, exerce a tradução como se essa, mais do que traduzir, pudesse comunicar; é quando, portanto, as duas tarefas se confundem: o que é apenas traduzível passa a querer ser comunicável.

Nesse caso, poder-se-ia abster da expressão "comunicação", deixando-a para as abelhas, para tratar somente da tradução. Entretanto, insiste-se na primeira porque se pensa que a tradução é uma comunicação, porém, imperfeita. A imperfeição não é uma desvantagem, pelo contrário, é nessa imperfeição que se tem margens para criar, valorar a vida e fazer arte. 
Gabriel Sausen Feil é professor no curso de Comunicação Social e no curso de Especialização em Imagem, História e Memória das Missões, ambos da Universidade Federal do Pampa (UNIPAMPA); é doutor em Educação pela Universidade Federal do Rio Grande do Sul (UFRGS) e membro do Grupo de Pesquisa DIF - partistagens, fabulações, variações e Diálogos do Pampa; e líder do GP t3xto.

gabriel.sausen.feil@gmail.com

\section{Referências}

DELEUZE, G; GUATTARI, F. 20 de novembro de 1923 - postulados da linguística. In:

Mil platôs - capitalismo e esquizofrenia. vol. 2. Rio de Janeiro: Editora 34, 1995a.

_ 1933 - micropolítica e segmentaridade. In: Mil platôs - capitalismo e esquizofrenia. vol. 3. Rio de Janeiro: Editora 34, 1995 b.

700 a.C. - aparelho de captura. In:

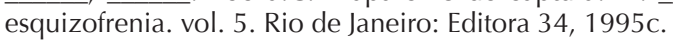
Mil platôs - capitalismo e HOHFELDT, A. As origens antigas: a comunicação e as civilizações. In: HOHFELDT, A.; MARTINO, L. C.; FRANÇA, V. V. (Org.). Teorias da comunicação: conceitos, escolas e tendências. Petrópolis: Vozes, 2001.

MARTINO, L. C. De qual comunicação estamos falando? In: HOHFELDT, A.; MARTINO, L. C.; FRANÇA, V. V. (Org.). Teorias da comunicação: conceitos, escolas e tendências. Petrópolis: Vozes, 2001a.

. Interdisciplinaridade e objeto de estudo da comunicação. In: HOHFELDT, A.; MARTINO, L. C.; FRANÇA, V. V. (Org.). Teorias da comunicação: conceitos, escolas e tendências. Petrópolis: Vozes, $2001 \mathrm{~b}$.

NIETZSCHE, F. W. A gaia ciência. São Paulo: Companhia das Letras, 2012.

. Assim falava Zaratustra: um livro para todos e para ninguém. Lima: Los Libros Mas Pequeños Del Mundo, 2010. Letras, 2005.

Além do bem e do mal: prelúdio de uma filosofia do futuro. São Paulo: Companhia das

A filosofia da época trágica dos gregos. In:

Obras incompletas - Friedrich Nietzsche. São Paulo: Abril Cultural, 1978a.

Sobre verdade e mentira no sentido extramoral. In: Obras incompletas - Friedrich Nietzsche. São Paulo: Abril Cultural, 1978b.

. Humano, demasiado humano. In: Obras incompletas - Friedrich Nietzsche. São Paulo: Abril Cultural, 1978c.

TADEU, T.; CORAZZA, S. M.; ZORDAN, P. Linhas de escrita. Belo Horizonte: Autêntica, 2004.

VIGOTSKI, L. S. A construção do pensamento e da linguagem. São Paulo: Martins Fontes, 2000. 